PAULINA FRANCISCA GONZÁLEZ VALENZUELA

INSTITUTO DE ESTÉTICA

FACULTAD DE FILOSOFÍA

PONTIFICIA UNIVERSIDAD CATÓLICA DE CHILE

SANTIAGO, CHILE

PFGONZA2@UC.CL
Este artículo sintetiza parte de los resultados de la investigación "Soportes Visuales de Resistencia: Diseño editorial no oficial de Chile en dictadura (1973-1989)", Proyecto FONDART Nacional 2014, folio 44683

Fecha de recepción: 24/04/2017

Fecha de aceptación: 30/06/2017

Cómo citar: González Valenzuela, P. F. (2017)

Publicaciones culturales de resistencia durante la dictadura: estudio de tres casos de representación visual. RChD: creación y pensamiento, 2(2). 1-11

DOI: 10.5354/0719-837X.2017.46372

\section{Publicaciones culturales de resistencia durante la dictadura: estudio de tres casos de representación visual}

\author{
Cultural Resistance Publications During the Military Dictatorship: \\ A Study of Three Cases of Visual Representation
}

Resumen. El presente artículo aborda la resistencia cultural desarrollada durante el período dictatorial en Chile (1973-1989), desde la mirada de tres publicaciones que formaron parte de las redes de expresión artística erigidas al margen del discurso oficial: Palabra Escrita, La Bicicleta y La Castaña. Mediante la revisión de la experiencia productiva de estos medios, se propone ejemplificar las variantes de una disyuntiva estética que definió formas antagónicas de representar la escena cultural post golpe; las cuales encuentran su origen tanto en la influencia de los relatos sociales colindantes a sus espacios de circulación, como en el acceso a determinados medios de producción y manejo técnico.

Palabras clave: dictadura, resistencia, revistas culturales, visualidad.

\begin{abstract}
The present article takes as a starting point the cultural resistance developed during the military dictatorship in Chile (1973-1989), using the point of view of three publications that took part of the artistic expression networks that existed beyond the limits of the official statement: Palabra Escrita, La Bicicleta and La Castaña magazines. The review of the productive experience of these media is proposed, identifying the variants of the aesthetic dilemma that defined the opposing forms of representation of the cultural post-coup scene. These found their origins both in the influence of the adjoining social narratives over their own spaces of circulation, and in the access to specific means of production and technical management. Keywords: cultural magazines, dictatorship, resistance, visuality.
\end{abstract}

Revista Chilena de Diseño,

RChD: creación y pensamiento

Universidad de Chile

2017, 2(2)

http://rchd.uchile.cl 
1. Entre sus características destaca el uso de nomenclatura e iconografía local, y el énfasis en un imaginario de izquierda representado en una combinación de estilos como el Pop Art, la psicodelia y la expresividad muralista. La presencia de estas corrientes alcanzó gran recepción al interior de la producción impresa, cuya reproductibilidad -a través de técnicas como el offset, la serigrafía y el cliché tipográfico (Vico, 2014, p. 293)- los desmarcó del ámbito de las artes favoreciendo su ingreso a la cultura popular de masas.

2. Esta deslegitimación a nivel cultural se grafica en lo que Luis Hernán Errázuriz (2009), define en tres procesos: Limpieza, corte y restauración. El primero de estos, incluye la eliminación de murales emblemáticos, el cambio de nombres de calles, edificios y poblaciones, el desmantelamiento de sedes políticas, la intervención en universidades estatales y centros deportivos, el control de áreas estratégicas de comunicación como la Editora Nacional Quimantú, la confiscación (y quema) de libros y material fílmico, la clausura (y atentados) a organizaciones del mundo de la cultura, así como la represión y persecución de artistas progresistas y sus obras. La segunda, de tinte valórico, mermó en el habitus colectivo al imponer una nueva escópica en la juventud en un intento por aplacar la influencia visual del pensamiento de izquierda. Por tal motivo, se externalizaron características conservadoras ligadas a lo militar, incluso mediante una prohibición del uso de los colores negro y rojo en rechazo al aparataje revolucionario. Finalmente la etapa de restauración, se vinculó en torno al concepto de "la chilenidad" con el objetivo de recuperar la identidad y el sentido de la nación. Con ello se reconfigura lo "patrimonial" a través de las antiguas casas de campo chilenas que habían sido abandonadas luego de la Reforma Agraria; se generan monumentos y episodios de conmemoración que exaltan las glorias del Ejército; y se reordena el capital cultural en búsqueda de lo "auténticamente" chileno a través del folclor sin compromiso político, y la sobreexhibición de los símbolos patrios.

3. Entre estos se encuentran los periódicos $E l$ Siglo, El Rebelde, Puro Chile, Las Noticias de Última Hora, El Clarín y la revista Punto Final.

\section{Introducción}

Diversos acercamientos a la visualidad desarrollada en Chile desde mediados del siglo $x x$, han resituado en la memoria colectiva la existencia de una serie de soportes gráficos, de marcado compromiso político, que alcanzaron notoriedad como medios representativos de los procesos históricos contemporáneos.

La revisión de este material, visible en la publicación de variadas investigaciones interdisciplinares (Castillo, 2010; Errázuriz y Leiva, 2012; Valdebenito, 2010; Vico, 2013; Vico y Osses, 2013; Cristi y Manzi, 2016), permite vislumbrar el alcance de algunas prácticas de construcción visual que, más allá de responder a un área artística, se erigieron como medio de legitimación de grupos e instituciones sociales. Su función persuasiva replicó los lineamientos ideológicos propios de un dispositivo medial como un modo de determinar las conductas y opiniones de los individuos desde la difusión de códigos visuales específicos. La creación de formas gráficas aprendidas en el oficio y/o influencia de estéticas colindantes, hizo posible reconocer, sobre todo durante la década de los sesenta y principios de los setenta, la consolidación de una identidad gráfica ${ }^{1}$ marcada por la ideologización y las reformas sociales.

El golpe de Estado en 1973, dio paso a la deslegitimación pública² de cualquier forma de expresión vinculada a los recientes procesos modernizadores, siendo uno de sus principales efectos el desmantelamiento de espacios informativos opuestos a la ideología sustentada por el régimen³. El alcance de esta modalidad, especialmente ante la prohibición de instaurar nuevas plataformas, provocó "un estrechamiento de la diversidad del sistema comunicativo" (Munizaga, 1983, p. 9) que delimitó la representatividad del sujeto social al interior de los medios masivos y acentuó una discontinuidad histórica que relegó a la cultura popular, y por tanto a parte de la identidad nacional, a un estado de invisibilización. Tal hegemonía llevó a cabo un continuo desarrollo de prácticas que violaron los derechos humanos en diversas áreas de participación social, favoreciendo la difusión de los planteamientos refundacionales del discurso oficialista, y creando con ello "una cultura disciplinaria, donde la clase dominante asumió íntegramente la dirección de los procesos de autoformación de la sociedad, imponiendo la exclusión política de las demás clases y reduciéndolas a una combinación de represión y conformismo" (Donoso, 2012, p. 3).

A consecuencia de este hecho, y ante el estado fragmentario de muchas organizaciones de base, es que surgió la necesidad de crear focos de resistencia que unificaran a la sociedad chilena mediante la emergencia de proyectos alternativos, cuyo accionar se instauró en clandestinidad conformando un repliegue creativo que entre 1974 y 1980 (Salazar y Pinto, 1999, p. 235), dio inicio a una nueva identidad generacional adentrada en refugios subterráneos de reagrupación, introversión y resistencia, como lo fueron las peñas, talleres culturales, centros universitarios, sindicatos y sedes parroquiales. Esta paulatina reconfiguración del movimiento sociocultural, sentó las bases para la producción de soportes como el cartel, el panfleto y medios editoriales de diverso formato, que demarcados por la marginalidad y la escasez de recursos, dieron paso a expresividades que "no pueden ser entendidas como simple evolución de un lenguaje visual consolidado en los años previos, sino como una manifestación gráfica que hereda dicho imaginario y que responde a la especificidad de su momento histórico" (Cristi, 2013, p. 84). 


\section{Medios editoriales en el circuito cultural de resistencia}

A diferencia de otras expresiones, la aparición de los primeros formatos editoriales constituyó el inicio de una experiencia de comunicación popular que concibió formas de identificación y pertenencia, capaces de instaurar vías de acceso a entidades sociales que habían tenido una importante participación en el proceso político anterior (Subercaseux, 1988, pp. 5-6). Su constitución de carácter local respondió al hecho de ser el único espacio donde "afloraron prácticas de 'resistencia defensiva' e iniciativas de afirmación de identidad" (ECO y Ortega, 2012, p. 28) que acentuaron la necesidad de constituir instancias expresivas desde diferentes temáticas y subjetividades, principalmente ligadas a la defensa de los derechos humanos, la difusión cultural, el periodismo alternativo y el creciente movimiento asociado a grupos sindicales, feministas, estudiantiles y poblacionales.

Desde una transversalidad de discursos, estas publicaciones periódicas se articularon como lugares de mediación entre el sujeto social y las instituciones productoras, generando espacios de intercambio, entre una vasta red de agrupaciones sociales, con el fin de organizar, educar e informar a la población. De este modo, sus contextos productivos se sustentaron en la autogestión y el aprendizaje colectivo, imprimiendo en el corpus del objeto distintas formas de representar la contingencia mediante recursos técnicos y códigos simbólicos pertinentes.

Específicamente al interior del circuito cultural, la publicación de medios impresos se replicó al interior de organismos universitarios como el Departamento de Estudios Humanísticos de la Universidad de Chile (revista Manuscritos) y la Agrupación Cultural Universitaria, ACU (El Pasquín, La Ciruela, Pilca); espacios artísticos como la Galería CAL (Revista CAL) y el Taller T.A.V. (Boletín

T.A.V.); talleres literarios y de poesía como los Talleres Andamio y Fragua (con ediciones del mismo nombre); lugares de encuentro como la peña Doña Javiera (Javiera, revista cultural) y la Casona de San Isidro (Revista Cultural La Casona de San Isidro); y agrupaciones como la Asociación Metropolitana del folklore de Chile (Boletín AMFOLCHI), la Sociedad de Escritores de Chile (Boletín informativo $S E C H$ ), el Colectivo de Escritores Jóvenes (Hoja x Ojo, Boletín Unión Literaria), entre otros. Aunque también las hubo desde iniciativas particulares o colectivas sin afiliación reconocida.

Todas estas instancias, formadas mayoritariamente por jóvenes vinculados a áreas artísticas diversas, tuvieron como problemática común la imposibilidad de difundir sus creaciones al interior del circuito público. Por este hecho es que la producción editorial se transformó en una importante plataforma para hacer, registrar y diseminar, en diferentes regiones, el accionar disidente de un movimiento cultural que expresó - por medio del arte, la literatura, el teatro y la música- un mensaje de resistencia ante la hostilidad del período.

Este modo de revertir la situación de marginalidad y hacer frente a lo impuesto por la dictadura, se convirtió en un ejercicio de paulatina proliferación que alcanzó su punto más álgido a mediados de la década de los ochenta. No obstante, así como aumentaron los colectivos culturales, y con ello la producción de publicaciones periódicas, también desaparecieron otros espacios, dejando a la deriva un sinnúmero de revistas y boletines que no alcanzaron reconocimiento entre sus pares, o simplemente no lograron proyectarse más allá de las primeras ediciones. Pese a las diferencias técnicas, producto de la experiencia productiva, el acceso a mejor tecnología y la capacidad de autofinanciamiento, la mayor disyuntiva estética presente en estas expresiones se denota en el desarrollo 
4. De circulación marginal, Palabra Escrita participó de redes de intercambio y de venta esporádica, no superando los mil ejemplares. Se publica hasta el día de hoy en formato web: http://www. palabraescrita.cl/

5. El Tallersol es un Centro Cultural dirigido por Antonio Kadima, que se estableció en 1977 enfatizando la cultura y las artes como un modo de resistencia a la dictadura. En él, se desarrolló un trabajo conjunto con comunidades de base mediante el apoyo en materias diversas, donde se abordó la creación literaria y visual a través de soportes gráficos como el cartel y las revistas literarias. Actualmente, se encuentra emplazado en Av. Portales 2615 (esquina Cueto, Barrio Yungay), manteniendo actividades culturales autogestionadas, y resguardando importante material documental de la época a través del Archivo Memoria de la Resistencia, el Centro de Documentación Patricio Sobarzo y la Biblioteca Barrial Claudia López. de una visualidad solventada por el uso de códigos simbólicos particulares, en desmedro de la identificación colectiva del movimiento cultural no oficial. Este hecho tiene su explicación en la diseminación de una multiplicidad de focos creacionales, sus experiencias disímiles ante el contexto sociopolítico, la influencia de relatos y estilos contiguos a sus áreas de circulación, y el consecuente carácter efímero de sus propuestas.

Sin embargo, tras la revisión de un vasto corpus de publicaciones vinculadas a la resistencia, fue posible identificar el dominio de al menos dos ejes de representación: por un lado, y mayormente desde las bases, la rigurosidad de un estilo solventado en la reivindicación de símbolos contestatarios; y por el otro, la incidencia de componentes alternativos que desde un pluralismo discursivo -reseñado en la inclusión de nuevas voces de la resistencia social- resignificaron los códigos del imaginario cotidiano a partir de la experimentalidad y/o mediante el uso de códigos visuales cercanos a la cultura popular de masas. A partir de esta premisa, es que el presente artículo propone un análisis de la visualidad presente en las revistas Palabra Escrita, La Bicicleta y La Castaña, ejemplificando en la peculiaridad de sus contextos de creación las diferentes formas de concebir el ideario cultural de la resistencia. El enfoque metodológico utilizado apela a la revisión de sus discursos, variantes gráficas y contextos socio-productivos para comprender las motivaciones en torno a sus planteamientos expresivos.

Palabra Escrita: Creación literaria y reivindicación de símbolos contestatarios Tras experiencias preliminares que no lograron mayor continuidad, como Nueva Línea (1975) y Planeta de Flory de Barro (1978), el poeta ariqueño José Martínez Fernández se encauzó a la producción de una nueva revista literaria que retomara su interés por los nuevos exponentes de la escena nacional que mantenían un compromiso de responsabilidad con su arte frente a la contemporaneidad.

Así, en 1979, nació Palabra Escrita, publicación que se erige como uno de los medios culturales con mayor tiempo en circulación 4 .

Sólo hasta el fin de la dictadura, la revista publicó más de veinte números que evocaron, al igual que muchas de sus coetáneas, una estética mecánica implícita en textos mecanografiados, imágenes fotograbadas y el uso de sistemas de impresión offset en matriz de papel, cuya presencia demarcó una producción autónoma y económica.

Mediante líneas escriturales breves, como el ensayo y la poesía, su formato de $16 \times 21 \mathrm{~cm}$ alcanzó una extensión que osciló entre 4 y 22 páginas que fueron reproducidas, y compaginadas, en imprentas ubicadas en las ciudades de Arica y Tacna hasta 1980. La lejanía de estos lugares, así como el acceso a tecnología más económica, favoreció la aplicación de variantes cromáticas poco utilizadas al interior del circuito disidente, especialmente a consecuencia de una escasez de recursos que había asentado el uso del negro como signo referencial de las producciones marginales.

Su posterior traslado a Santiago y la incorporación del poeta y artista gráfico Antonio Kadima entre sus colaboradores, instauraron en la revista un desarrollo visual acorde a un discurso de izquierda que dio cabida al uso de técnicas -como el collage, el grabado y el alto contraste- que tenían un estrecho vínculo con el trabajo realizado por Kadima al interior del Tallersols. Si bien dichas técnicas no añadieron estructura a la diagramación de las páginas, sí fueron de gran relevancia en la composición de las portadas, donde las citas 

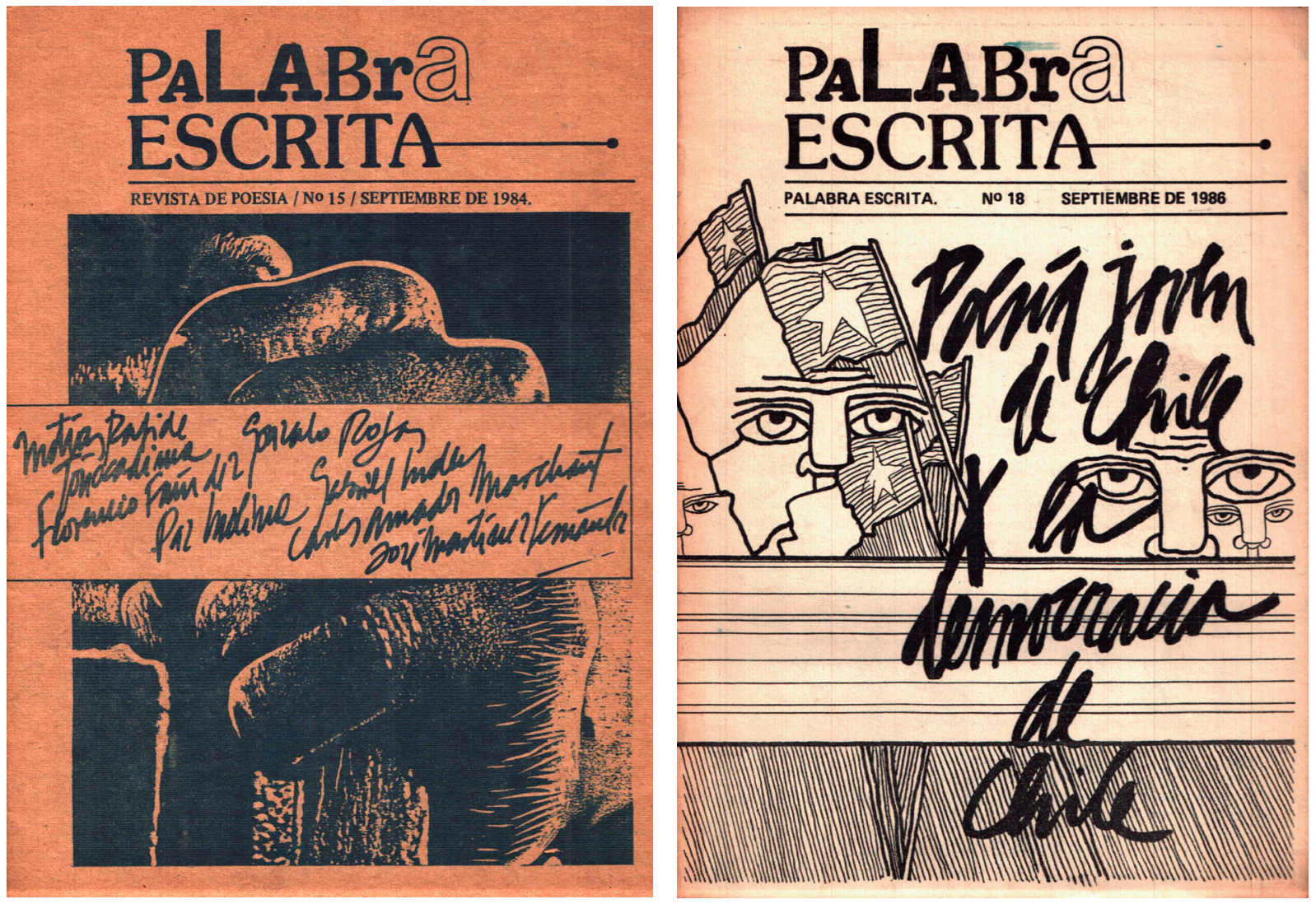

al cartel de resistencia se convirtieron en una propuesta visual tanto en lo relativo a la composición tipográfica (letras rotuladas, alfabetos reciclados), como en la apropiación de un imaginario -de raigambre revolucionario y latinoamericano- que había perdido su hegemonía sociocultural.

En un contexto de crisis económica y protestas nacionales (1983-1986), Palabra Escrita reivindicó, por medio del dibujo en tinta y la intervención fotográfica, algunos elementos iconográficos como la mujer pobladora, la mano empuñada, la silueta del combatiente, la bandera en alto, y una serie de ilustraciones inspiradas en el trazo de las brigadas muralistas, cuya presencia potenció una postura crítica y de denuncia frente a los sucesos del período. Para Bernardo Subercaseux (1985) la representación de esta lectura política que unificó lo popular con la acción contestataria, responde a una tradición latinoamericana que identifica al movimiento de izquierda con las expresiones populares (p. 7), cuya reivindicación simbólica en el marco de la resistencia social contra la dictadura, constituyó el activo de una memoria histórica que fue resguardada como vía de acceso "a los valores de identidad nacional y popular que debían ser protegidos como lazos de integración comunitaria" (Richard, 1994, p. 24). De esta manera, Palabra Escrita fue capaz de reforzar su contenido direccionando sus temáticas hacia la nostalgia por los proyectos sociales del pasado, dando paso a la reapropiación de aspectos léxicos e iconográficos que fueron adaptados en razón de los acontecimientos. Sin embargo, el alejamiento de Kadima en 1987 significó el declive paulatino de este tipo de expresiones, favoreciendo el uso de códigos neutrales que fomentaron el carácter literario replicado por la revista.
Figura 1. Portada Palabra Escrita $n^{\circ} 15$, septiembre de 1984. Fuente: Archivo Memoria de la Resistencia, Centro Cultural Tallersol.

Figura 2. Portada Palabra Escrita ${ }^{\circ} 18$, septiembre de 1986. Fuente: Archivo Memoria de la Resistencia, Centro Cultural Tallersol. 

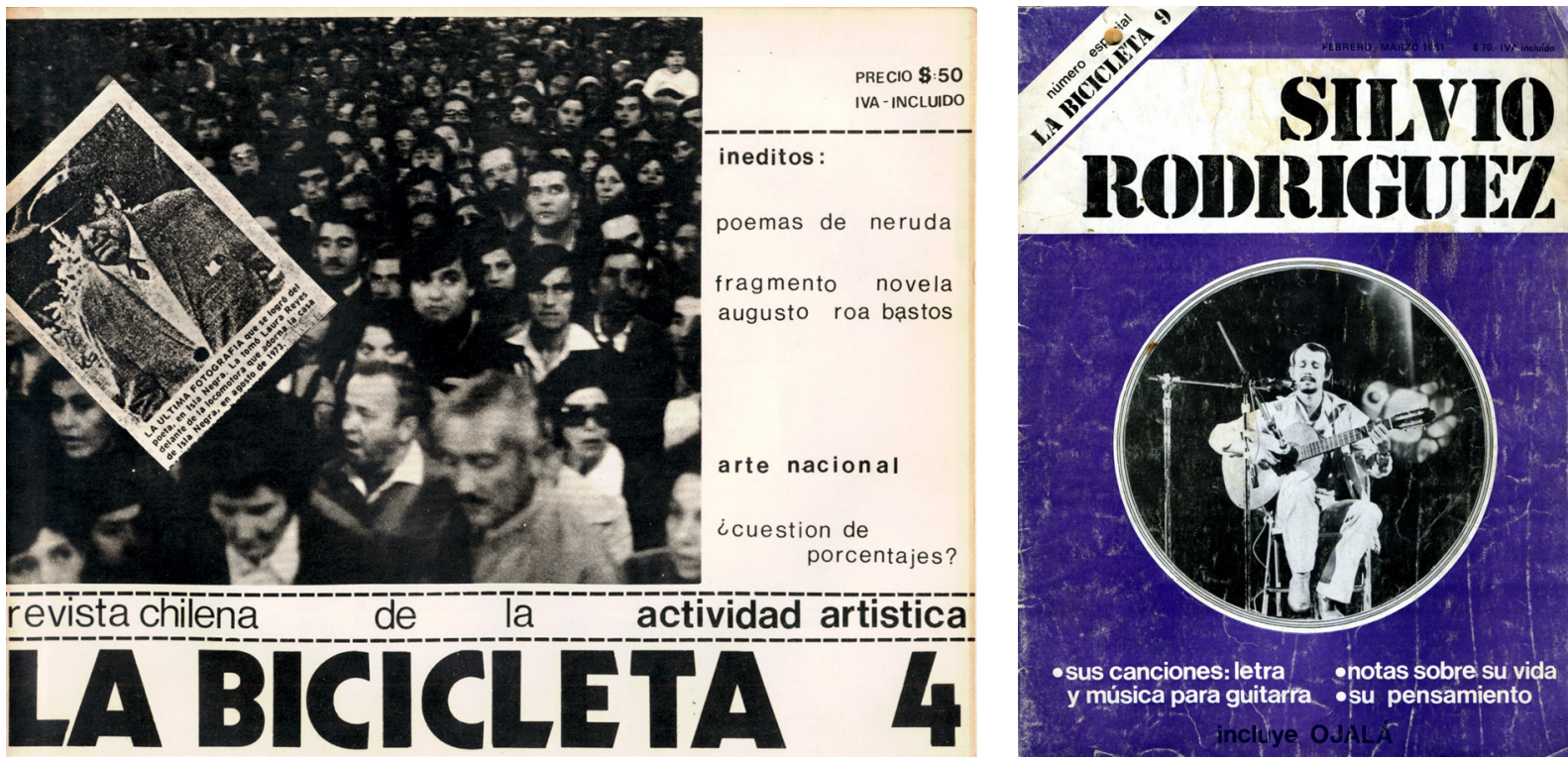

Figura 3. Portada La Bicicleta $n^{\circ} 4$, agosto-septiembre de 1979. Fuente: Colección del autor. Figura 4. Portada La Bicicleta ${ }^{\circ} 9$, febrero-marzo de 1981. Fuente: Colección del autor.

6. La Unión de Jóvenes Democráticos (UJD) perteneció a las Juventudes del MAPU-OC. La participación de Yentzen hasta 1980, posibilitó que esta entidad financiara el primer ejemplar de la revista.

7. La mayoría de sus integrantes y colaboradores formaron parte de organismos como la Agrupación Cultural Universitaria (ACU), la Unión de Escritores Jóvenes (UEJ) o la UJD.

8. Para poder circular libremente, las publicaciones autorizadas debían mostrar su contenido en las oficinas de la Dirección Nacional de Comunicación Social (DINACOS), ente encargado de fiscalizar y censurar cualquier material que no cumpliera con lo expuesto por el régimen. Entre sus objetivos se encontraba la revisión e intervención de la prensa escrita y radial, dando cuenta de los límites informativos, a directores y editores, con el fin de lograr la autocensura de los propios medios.

9. Término incorporado por la revista Manuscritos (1975) como una forma de contextualizar el trabajo de diagramación realizado por la artista visual Catalina Parra. Su definición, recae en la amplitud
La Bicicleta: Resignificación y experimentalidad en la gráfica de los ochenta En un escenario totalmente distinto, fue publicado en 1978 el primer número de la revista La Bicicleta, la cual se ideó como una plataforma comunicativa orientada a la difusión de las diversas actividades vinculadas al movimiento cultural disidente. La creciente ampliación de esta escena, así como la posibilidad de crear un medio impreso de libre circulación en el espacio oficial, estableció el ambiente propicio para que Eduardo Yentzen, en ese entonces adherente a la Unión de Jóvenes Democráticos (UJD) ${ }^{6}$, fundara este proyecto junto a un colectivo interdisciplinario de común trayectoria en el mundo cultural universitario,7 entre quienes estaban Álvaro Godoy, Anny Rivera y Paula Edwards. Su discurso de carácter pluralista la hizo acreedora de una visualidad que rompió con la "épica contestataria" (Castillo, 2010, p. 147) reproducida al interior del circuito de resistencia, estableciéndose como una de las revistas culturales con mayor presencia en el espacio público. Así, fueron publicados 75 números (más una serie de ediciones especiales) que se caracterizaron por mantener una visión de vertiente alternativa "portadora de nuevas formas y estilos de discursos" (Richard, 1994, p. 57). La representación inicial de estas perspectivas sorteó los efectos de la censura, ${ }^{8}$ configurando una diagramación acorde a su interés por el desarrollo de las artes (Yentzen, 2014, p. 53) que fomentó -a través de un formato apaisado- un distanciamiento de la rigidez estructural mantenida por otras publicaciones, a fin de potenciar la libertad creativa e incluir propuestas visuales menos convencionales. Sin embargo, fue recién en la edición de su cuarto número que la revista alcanzó una construcción visual concreta, dando cabida a propuestas estéticas cercanas a la "Escena de Avanzada" como resultado de la participación de los artistas del CADA Lotty Rosenfeld y Juan Castillo. Esto constituyó un cambio significativo en la sintaxis de las tramas compositivas, incorporando un trabajo de "visualización"9 que propició la simpleza de elementos gráficos mayormente encriptados, contribuyendo a reforzar un carácter persuasivo mediante la jerarquización de los títulos y la añadidura de montajes fotográficos y textos referenciales a las distintas secciones desarrolladas por la publicación. 

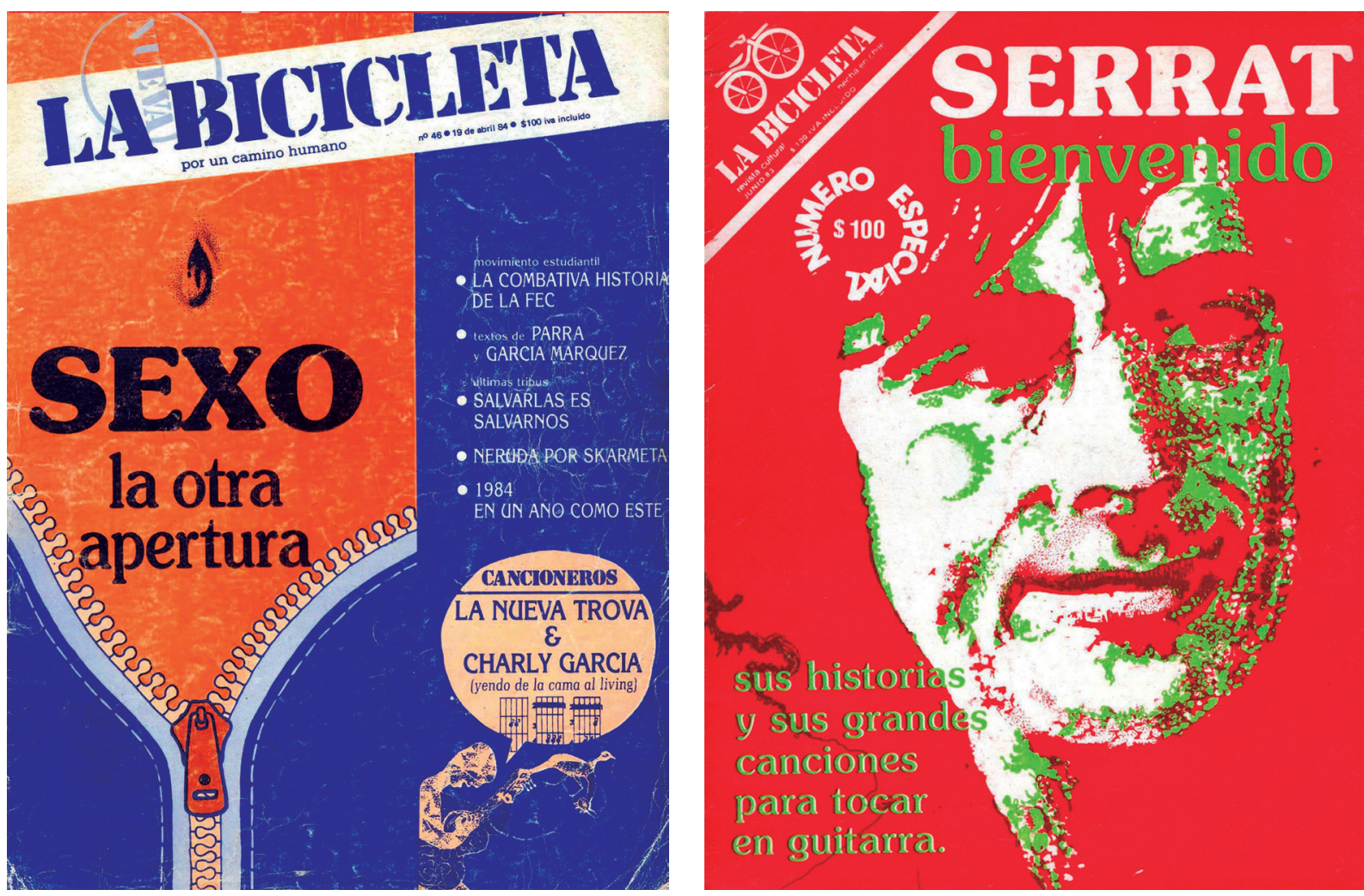

Si bien gran parte de estas modificaciones se mantuvieron hasta 1981, la edición de su noveno número marcó un punto de ruptura con el enfoque estrictamente cultural que había adoptado desde sus inicios, integrando contenido de discusión marginal como la música contestataria, la ecología, el esoterismo y la sexualidad, que redireccionaron la narrativa de la revista hacia un público primordialmente juvenil. Esta variación, que inscribió al "cancionero" como un importante objeto de resignificación, dio espacio mayoritario a la inclusión de músicos internacionales identificados con la canción de protesta como Silvio Rodríguez, Joan Manuel Serrat, Chico Buarque y Joan Báez; a nivel nacional, se destacó también a artistas vinculados a la Nueva Canción Chilena como Víctor Jara e Inti Illimani, y al Canto Nuevo como Santiago del Nuevo Extremo, Schwenke y Nilo, entre otros. En ambos casos, el uso de la imagen del artista en primera plana permitió ahondar en estrategias visuales que mitigaran el alcance de una eventual lectura política de estos íconos en favor de su conformación mediática como referentes de la cultura popular de masas. De acuerdo a Ignacio Reyes, ${ }^{10}$ diagramador de La Bicicleta, este desarrollo experimental se sustentó en un trabajo de efectismo gráfico que explotó al máximo las capacidades expresivas de las portadas. Tanto la manipulación fotomecánica y la intervención en matrices de imprenta, hicieron posible la reutilización de elementos como los negativos, el descalce, la saturación y la mezcla de colores, al igual que el empleo de recursos como la impresión en duotono, el alto contraste, los revelados sucesivos y la trama fotográfica. Además, se realizó una intervención de carácter manual mediante algunas variantes visuales como el collage, la ilustración y el humor gráfico, ${ }^{11}$ así como la simulación de texturas en las fotografías mediante herramientas como los rotuladores a tinta.
Figura 5. Portada La Bicicleta $n^{\circ} 46$, abril de 1984 Fuente: Colección del autor.

Figura 6. Portada La Bicicleta número especial, junio de 1983. Fuente: Colección del autor.

de significados generados por la interacción entre elementos textuales y visuales, creando propuestas -con finalidades teóricas y gráficasque fueron incorporadas como una estrategia de diagramación al interior de las ediciones de artes visuales (Raveau, 2013, p. 12). Entre ellas, catálogos $u$ otras revistas cuya visualidad fue correlativa a un público especializado (artistas, escritores) lejano a las audiencias populares.

10. Entrevista personal, 15.10.2013.

11. El humor gráfico de la revista estuvo a cargo de la historieta cómica Supercifuentes, creada por el dibujante Hernán Vidal (Hervi). Esta relataba las aventuras de un superhéroe de clase media que luchaba contra las injusticias sociales propias de los años ochenta. 
12. Finalmente, la revista mantuvo un formato de $21 \times 27.9 \mathrm{~cm}$, y 44 páginas de extensión. En ella se desplegó una estructura visual acabada, con énfasis en la jerarquización visual y el justificado, generando niveles de información con todos los datos distribuidos en la página, ya sea variando el tamaño de los caracteres o utilizando recursos cromáticos que develaron un mayor contraste entre sus unidades. El uso fotográfico e ilustrativo develó mayoritariamente una participación complementaria en relación al resto del contenido.

13. Excepcionalmente, fue editado en 1990 un número especial dedicado a la conmemoración de la vuelta a la democracia.

14. Entre estos destaca la creación de carátulas y carteles alusivos al sello DICAP (Discoteca del Cantar Popular) en los que junto a los hermanos Vicente y Antonio Larrea, también participaron Hernán Venegas y Luis Albornoz, entre otros (Castillo, 2010, p.113).

15. Las experiencias anteriores de Montealegre en la producción de micromedios culturales,
(1980-1982), influyeron notoriamente en la definición de un lineamiento humorístico vinculado al absurdo, que se erigió como una constante hasta 1987, momento en que salió a circulación su último número.

16. Venegas, Hernán. Entrevista personal, 05.10 .2013 .
La paulatina estandarización de su formato, ${ }^{12}$ el asentamiento de su identidad gráfica y la inclusión de temáticas representativas de la generación de los ochenta, consolidaron la incidencia social de la revista articulando una posición ideológica en el escenario político que estableció -a partir del consumo, uso y apropiación de sus códigos- un lugar de disidencia en el cual se expresó la emergencia de nuevas subjetividades entre la juventud chilena (Osorio, 2011, pp. 274-275). La visibilidad alcanzada, sobre todo tras superar los 10 mil ejemplares, propició que en noviembre de 1984, tras el estado de sitio decretado por las autoridades, se prohibiera su circulación en quioscos durante los meses siguientes.

Pese a superar este incidente y a retomar su circulación periódica, la revista dejó de publicarse en $1987^{13}$ tras perecer bajo las inclemencias del desfinanciamiento.

\section{La Castaña: Intencionalidad gráfica y nuevas representaciones estéticas} Surgida como tal en 1982, La Castaña se constituyó en una plataforma de confluencia inédita al reunir a los jóvenes literatos de la generación de los ochenta y a los artistas gráficos que durante la década anterior habían participado en la creación de imágenes asociadas al período de la Unidad Popular. ${ }^{14}$ Sus siete números, editados por un colectivo interdisciplinario formado por los escritores Jorge Montealegre y Pía Barros en conjunto con los gráficos Jorge Soto Veragua, Luis Albornoz y Hernán Venegas, se conformaron bajo ejes conceptuales como la poesía, la gráfica y el humor ${ }^{15}$ configurando un espacio de manifestación que se alejó de las lecturas unificadoras y globalizantes del imaginario popular (Subercaseux, 1985, p. 19). Para ello, integraron códigos neutrales que apelaron a la autonomía estética de variantes expresivas como la ilustración, la caricatura y la historieta, a través de las colaboraciones de destacados exponentes como Alejandro Montenegro (Rufino), Hernán Vidal (Hervi), Luis Salinas (Aetós), José Palomo (Palomo), Guillo Bastías (Guillo), Eduardo de la Barra, Patricio Andrade y Antonio Larrea. Su formato de $16 \times 21 \mathrm{~cm}$, resignificó los códigos visuales establecidos desde su producción marginal, mediante el rescate de materialidades como el papel de envolver (kraft) y la monotonía del negro, intentando así generar un diálogo constante entre la dualidad de su condición que, por una parte, la convirtió en una alternativa capaz de difundir expresiones y temáticas que no tenían cabida al interior de otros espacios, y por otra, el nivel de profesionalismo de dicho contenido la situó en un estrato privilegiado respecto al resto de los medios circundantes.

La calidad visual expresada por La Castaña puso en evidencia una reflexión en torno a los lenguajes cercana a lo que Adriana Castillo (1993) define como una "voluntad rupturista", es decir, como una propuesta que se asume libre e independiente de cánones tradicionales y protecciones paternalistas, en favor del "reconocimiento del derecho a la diferencia, la acción estética múltiple y compartida, y la recuperación e integración del sentido colectivo identitario" (p. 340). De esta forma, la composición de la revista emergió como resultado de la convivencia integral entre diversos temas y estilos expresivos, cuya configuración estructural en la página responde a una estrecha relación que sitúa la figura ilustrada - de gran detalle y precisión técnica- por sobre la extensión ocupada por el texto. ${ }^{16}$ Esta intencionalidad gráfica, potenciada por el trazo en rotulador y el alto contraste, requirió de procesos fotomecánicos que permitieran ampliar o disminuir su tamaño real 

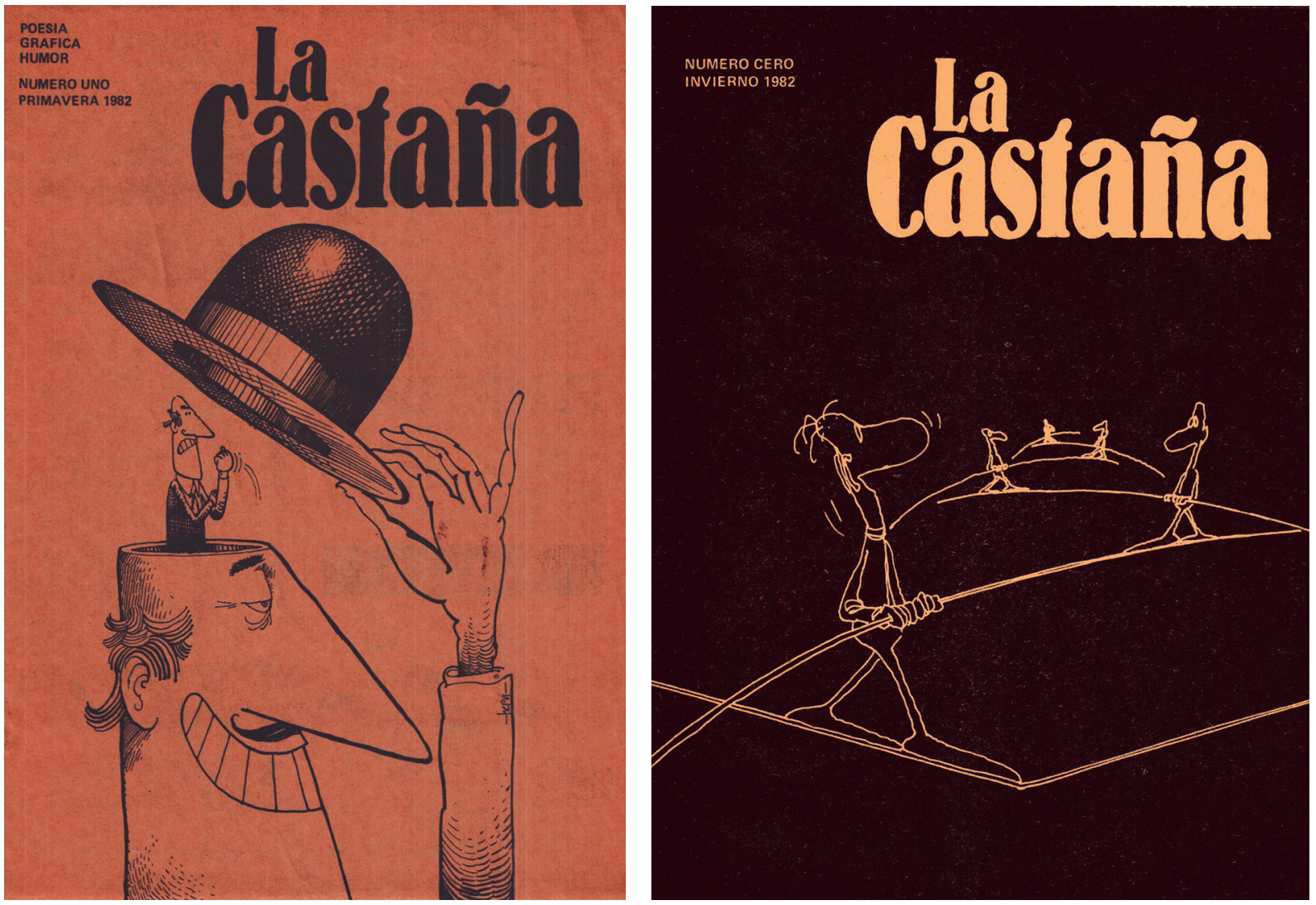

conforme a las posibilidades constructivas en el armado de los originales. Asimismo, el texto en su mayoría mecanizado coexistió junto a otros elementos tipográficos, como letras transferibles, alfabetos recortados y textos a mano alzada, que establecieron -a través del grosor de línea- una jerarquía visual en relación al resto del contenido.

Su extensión, que varió entre 16 y 28 páginas, dio muestras de una riqueza expresiva producto de la diversificación de elementos persuasivos en cada una de sus ediciones, requiriendo de una impresión offset de calidad capaz de definir correctamente las texturas generadas por el trazo de las ilustraciones. Pese a que parte de estas imágenes correspondieron a referencias de pequeños cuentos y ensayos, su estrecho vínculo con las temáticas de la contingencia nacional hicieron eco en secciones gráficas como "Castañuelas"; la cual, a partir de ilustraciones de Luis Albornoz, caricaturizó escenas de la cotidianeidad -como partidos de fútbol y calles peatonales- añadiendo frases con una hilarante crítica a la dictadura y el discurso oficial.

Con un tiraje semestral de $\mathbf{1 . 5 0 0}$ ejemplares, La Castaña se convirtió en una de las revistas con mayor proyección en la escena cultural de los años ochenta, distribuyéndose esporádicamente en las calles del Barrio Bellavista junto a su homóloga El Organillo. ${ }^{17}$ Su repercusión en la juventud, considerada por Montealegre como un efecto "sintomático" (Castillo, 1993, p. 341), generó un importante espacio de quiebre con el bloqueo estético y emocional impuesto por el régimen, contribuyendo a enfrentar la cultura del miedo que durante años había sometido a la sociedad chilena al silenciamiento.
Figura 7. Portada La Castaña $n^{\circ} 1$, primavera de 1982. Fuente: Archivo Memoria de la Resistencia, Centro Cultural Tallersol.

Figura 8. Portada La Castaña $\mathrm{n}^{\circ} 2$, invierno de 1982. Fuente: Archivo Memoria de la Resistencia, Centro Cultural Tallersol.

17. En El Organillo (1985-1990), revista especializada en literatura, participaron activamente Montealegre, Barros y Venegas. Su director Erwin Díaz, mantuvo los mismos códigos visuales de La Castaña, incluso su materialidad: el papel de envolver. 


\section{Consideraciones finales}

El ejercicio aquí propuesto, permite evidenciar un espectro de visualidades adyacentes al escenario cultural de resistencia a través de las distintas facturas, discursos e influencias estilíisticas visibles en las publicaciones revisadas. Su rescate actual como objeto de estudio constituye un acercamiento hacia iniciativas editoriales de las décadas precedentes cuyos planteamientos colectivos, vicisitudes productivas y estrategias visuales resaltaron su historicidad por medio de composiciones que traspasaron las fronteras del papel con el fin de repercutir ideológicamente en las subjetividad de sus lectores. Por un lado, Palabra Escrita transitó al interior de espacios dedicados a la literatura y poesía, fomentando la difusión y la validación de creaciones propias de la escena disidente. A diferencia de las otras revistas, la vinculación política de sus miembros y colaboradores fue determinante en la asociación de sus contenidos a una ideología de izquierda, que enfatizó la reproducción de iconografía revolucionaria como un modo de ilustrar parte de las consignas sociales atingentes. Sin embargo, esta remembranza a códigos visuales sometidos a la deslegitimación pública demarcó sus áreas de incidencia comunitaria, manteniendo una circulación esporádica que se restringió a espacios de distribución limitados.

Desde una arista contraria, La Bicicleta fue capaz de reinterpretar el significado de estos símbolos, utilizando un efectismo gráfico que disoció la relevancia política de reconocidos íconos contestatarios, en favor de una lectura ligada a la cultura de masas. El desarrollo de una mirada volcada en el presente le permitió configurarse como una publicación orientada a transmitir el accionar de la escena cultural de resistencia dando visibilidad al trabajo artístico de sus coetáneos.

Ya durante la década de los ochenta, la inclusión de nuevas voces cercanas a la contracultura le otorgó a la revista el sello juvenil que marcaría su reconocimiento a nivel nacional; derivando en un formato estándar similar al desarrollado por las revistas de circulación oficial. Además, el acceso a mejores recursos, y su posibilidad de distribución pública fueron determinantes para su asociación al imaginario social.

Por el contrario, La Castaña se situó desde un flanco de participación particular en el que profesionales del área gráfica y literaria ejercieron, en la intencionalidad del trazo, un modo de racionalizar los efectos visuales generados en favor de la conformación de una identidad gráfica sostenida en el tiempo. La revista se valió de la gráfica y el humor para la composición de la totalidad de sus páginas, causando una disrupción respecto a lo que se hacía en medios como La Bicicleta, en sus pequeños espacios dedicados a la caricatura.

Esta modalidad, que dotó a La Castaña de una visualidad de corte vanguardista, posibilitó la resignificación de material de uso cotidiano -como el papel de envolver- enfatizando una factura prolija determinada por la inclusión de modernas tecnologías. Situación que el resto de las publicaciones analizadas ejerció de manera improvisada al consolidar su lineamiento gráfico en una etapa tardía de su respectivo proceso creativo. La disyuntiva estética a la que se alude en este artículo responde entonces a la existencia de relatos fronterizos; colindantes en un espacio marginal que buscó recuperar la libertad de expresión mediante ejes simbólicos disímiles. Pese a que estas diferencias remarcan la imposibilidad de establecer un imaginario universal al interior de la colectividad cultural -como 
sí es observable dentro de otras temáticas vinculadas a la resistencia- es posible denotar en la creación de estas revistas una necesidad transversal de distintos grupos sociales por recuperar, en su rol de difusores culturales, los ejes de una identidad nacional que fue invisibilizada de los espacios de circulación tradicionales.

\section{Referencias}

Castillo, A. (1996). La Expresión de una voluntad rupturista: el discurso de La Castaña y El Organillo, revistas chilenas de los 80. América: Cahiers du CRICCAL, 15(1), 337-346. Castillo, E. (2010). Puño y Letra. Movimiento social y comunicación gráfica en Chile. Santiago: Ocho Libros.

Cristi, N. (2013) ¡A des-sitiar Chile! El afiche político en la clandestinidad, 1973-1989. En: M. Vico (Ed.). El afiche político en Chile 1970-2013 (pp. 79-107). Santiago: Ocho Libros.

Cristi, N. y Manzi, J. (2016). Resistencia gráfica. Dictadura en Chile. APJ-Tallersol. Santiago: LOM / CNCA.

Donoso, K. (2012). Discursos y políticas culturales de la dictadura cívico militar chilena, 1973-1988. Buenos Aires: Programa Buenos Aires de la historia política del siglo XX, 143-158. Recuperado de http://historiapolitica.com/datos/biblioteca/chile_donosofritz.pdf

ECO, y Ortega, J. (2012). La disputa por la palabra: Comunicación popular alternativa. Santiago: LOM.

Errázuriz, L. H. (2009). Dictadura militar en Chile: Antecedentes del golpe estético-cultural. Latin American Research Review, 44(2), 136-157.

Errázuriz, L. H. y Leiva, G. (2012). El Golpe Estético: Dictadura militar en Chile 1973-1989. Santiago: Ocho Libros.

Munizaga, G. (1983). Políticas de comunicación bajo regímenes autoritarios: El caso de Chile. En: El discurso público de Pinochet. Buenos Aires: CLACSO.

Osorio, J. (2011). La Bicicleta, el canto nuevo y las tramas musicales de la disidencia. Música popular, juventud y política en Chile durante la dictadura. 1976-1984. A Contra Corriente, 8(3), 255-286.

Raveau, N. (2013). Revista CAL, una historia. Santiago: Cociña, Soria Editores.

Richard, N. (1994). La insubordinación de los signos. Santiago: Cuarto Propio.

Salazar, G. y Pinto, J. (1999). Historia contemporánea de Chile V. Niñez y juventud. Santiago: LOM.

Subercaseux, B. (1982). Sobre la cultura popular. Santiago: Ceneca.

Valdebenito, F. (2010). Tinta Papel Ingenio. Panfletos políticos en Chile (1973-1990). Santiago: Ocho Libros.

Vico, M. (2013). El afiche político en Chile (1970-2013). Santiago: Ocho Libros.
Vico, M. (2014). La recepción del pop art en los diseñadores y los medios impresos: una manifestación de modernidad, 1967-1973. En: J. Concha y C. Robles (Eds.). Estética y Técnica en América Latina (pp. 293-308). Santiago: Pontificia Universidad Católica de Chile. Vico, M. y Osses, M. (2013). Un grito en la pared. Psicodelia, compromiso político y exilio en el cartel chileno. Santiago: Ocho Libros.

Yentzen, E. (2014). La voz de los setenta: Un testimonio sobre la resistencia cultural a la dictadura (1975-1982). Santiago: s.e. 